\title{
Plants traditionally used to make Cantonese slow-cooked soup in China
}

\author{
Yujing Liư ${ }^{1,5}$, Qi Liư ${ }^{1}$, Ping Li², Deke Xing ${ }^{1}$, Huagang $\mathrm{Hu}^{3}$, Lin Li ${ }^{1}$, Xuechen $\mathrm{Hu}^{5}$ and Chunlin Long ${ }^{4,5^{*}}$
}

\begin{abstract}
Background: Lăo huǒ liàng tāng (Cantonese slow-cooked soup, CSCS) is popular in Guangdong, China, and is consumed by Cantonese people worldwide as a delicious appetizer. Because CSCS serves as an important part of family healthcare, medicinal plants and plant-derived products are major components of CSCS. However, a collated record of the diverse plant species and an ethnobotanical investigation of CSCS is lacking. Because of globalization along with a renewed interest in botanical and food therapy, CSCS has attracted a growing attention in soup by industries, scientists, and consumers. This study represents the first attempt to document the plant species used for CSCS in Guangdong, China, and the associated ethnomedical function of plants, including their local names, part(s) used, flavors, nature, preparation before cooking, habitats, and conservation status.
\end{abstract}

Methods: In 2014-2017, participatory approaches, open-ended conversations, and semi-structured interviews were conducted with 63 local people and 48 soup restaurant owners (111 interviews) to better understand the biocultural context of CSCS, emphasizing ethnobotanical uses of plants in Guangdong Province, China. Product samples and voucher specimens were collected for taxonomic identification. Mention Index (QI), frequency of use index (FUI), and economic index (El) were adopted to evaluate the significance of each plant in the food supply.

Results: A total of 97 plant species belonging to 46 families and 90 genera were recorded as having been used in CSCS in the study area. Recorded menus consisted of one or several plant species, with each one used for different purposes. They were classified into 11 functions, with clearing heat being the most common medicinal function. Of the 97 species, 19 grew only in the wild, 8 species were both wild and cultivated, and 70 species were cultivated. Roots and fruits were the most commonly used plant parts in the preparation of CSCS. According to the national evaluation criteria, six of these species are listed on "China's red list" including two endangered, two critically endangered, one near-threatened, and one vulnerable species. The QI, FUI, and El of the 97 species in the study varied between 0.09 and 1, 0.23 and 9.95, and 0.45 and 6.58 , respectively.

Conclusions: As an important part of Cantonese culture, CSCS has been popularized as a local cuisine with a healthcare function. CSCS also reflects the plant species richness and cultural diversity of Guangdong Province. Future research on the safety and efficacy of CSCS as well as on ecological and cultural conservation efforts is needed for the sustainable growth of China's botanical and medicinal plant industry.

Keywords: Cantonese slow-cooked soup, Ethnomedicine, Botanical industry, Food therapy, Cultural significance indices

\footnotetext{
* Correspondence: long@mail.kib.ac.cn

${ }^{4}$ Kunming Institute of Botany, Chinese Academy of Sciences, Kunming,

Yunnan 650201, China

${ }^{5}$ College of Life and Environmental Sciences, Minzu University of China,

Beijing 100081, China

Full list of author information is available at the end of the article
}

(c) The Author(s). 2018 Open Access This article is distributed under the terms of the Creative Commons Attribution 4.0 International License (http://creativecommons.org/licenses/by/4.0/), which permits unrestricted use, distribution, and reproduction in any medium, provided you give appropriate credit to the original author(s) and the source, provide a link to the Creative Commons license, and indicate if changes were made. The Creative Commons Public Domain Dedication waiver (http://creativecommons.org/publicdomain/zero/1.0/) applies to the data made available in this article, unless otherwise stated. 


\section{Background}

In China, many communities have developed their own specific local type of soup, such as Simmer Soup in Hunan and Hubei provinces, Hot and Sour Soup in Sichuan province, Mutton Soup in Shandong province, and Cantonese slow-cooked soup (CSCS) in Guangdong Province. Among these soups, CSCS has the greatest number of varieties, and in general, it is well known locally and in foreign countries. As the name implies, CSCS is made with different kinds of ingredients from time to time and is cooked in a covered pot; the pot is allowed to simmer slowly at a low boil on a very low flame for an extended time. CSCS is a relatively low-fat, highly nutritious, and easily absorbed soup, used as a type of delicious appetizer, and has long been a form of traditional food therapy used by Cantonese people.

For a long time, CSCS and cooling herbal teas have epitomized Guangzhou food and drink culture [1]. The origin of CSCS can be traced back to 3500 years ago when it was used as an early form of Chinese herbal medicine [2]. Why? The heat and humidity of Guangdong inevitably penetrate the human body, making people feel very uncomfortable. Because Guangdong features a rich level of biodiversity, Chinese medicinal herbs are available for the Cantonese people to reduce a person's internal body heat or mitigate the humidity, but pure Chinese herbal tea is very bitter. Medicinal effects without this bitterness were desired. How was this problem solved? Clever Cantonese people added the medicinal herbs, such as ginger (Zingiber officinale Rosc.), which is used as an antinauseant [3], Lophatherum gracile Brongn., used to cure mouth and tongue sores [4], Zea mays L., used to induce diuresis [5], and the seeds of Euryale ferox Salisb. ex Konig \& Sims, which are used to cure kidney problems, to delicious soups [6].

Cantonese people have brought CSCS into many places where they live, such as Hong Kong, Macao, Taiwan, and other places in Southeast Asia as well as to the Chinatowns of different cities worldwide. CSCS provides a competitive advantage for immigrant Cantonese who markets this product in many places. However, many kinds of CSCS exist, so how does one select the right soup? Because many people lack an awareness of the use of traditional Chinese medicine (TCM) in support of human health, the development of CSCS has become disorganized. In addition, as food security has improved in recent years, international attention has been drawn to food therapy and food safety. As a result, the various types of CSCS need to be analyzed, so that the soup materials can be categorized according to their functions, part(s) used, preparation methods used before decoction and their nature (classified as hot, warm, cool, cold or neutral), and flavor. If these soup materials are classified and used correctly, the opportunity to develop Chinese medicine and expand food variety will emerge. In addition, it is imperative that steps are taken to preserve the heritage we have in TCM along with developing and protecting the nature of CSCS.

\section{Methods}

\section{Study area}

The coastal province of Guangdong is bounded by five southern Chinese provinces along with Hong Kong and Macao. Guangdong Province has a unique style with various dialects, customs, traditions, and historical culture. Guangdong covers an area of $179,800 \mathrm{~km}^{2}$ and has 56 ethnic minorities with the Lingnan culture being generally representative. The total population of Han nationality is 102 million in 2013, accounted for $97.46 \%$ of Guangdong Province; the population of Zhuang, Yao, Tujia, Miao, and Dong nationality accounts for $86 \%$ of the total ethnic minorities' population in Guangdong. The tropical and subtropical climates have a rich flora that thrives on a variety of geological features.

While Guangzhou serves as the capital of Guangdong Province, Shenzhen labels itself as an "emerging migrant city” (Fig. 1). Five villages (Mi Gang, Shi Hu, Luo Tang, Long Gang, and Bao An) and 48 restaurants in Guangzhou and Shenzhen were selected as the study sites. The criteria for selecting study sites, including soup chain stores and delivery outlets, were that the sites had a rich variety of CSCS materials so that the soup-drinking culture should be well preserved.

\section{Ethnobotanical surveys}

Our research findings are based on ethnobotanical surveys carried out from 2014 to 2017 with the objective of investigating, documenting, and interpreting which herbs Cantonese consumed in soup used to cure and prevent diseases and how these people produced and consumed these plants. A total of 63 local women in the five villages and 48 soup restaurant owners, both men and women, at other locations (111 interviews) were selected using participatory approaches, openended conversations, and semi-structured interviews (Fig. 1) [7]. The restaurant owners, all of whom had lived almost all of their lives in Guangdong, the local female residents over 40 years old, and could cook CSCS were invited to participate as informants; they all readily accepted the invitation to be interviewed. The study was carried out following the International Society of Ethnobiology Code of Ethics; all participants were informed of our intent prior to the start of the interviews. Prior to conducting interviews, we bought or took photos of plant materials used in restaurants in order to conduct a cross-validation of plant 


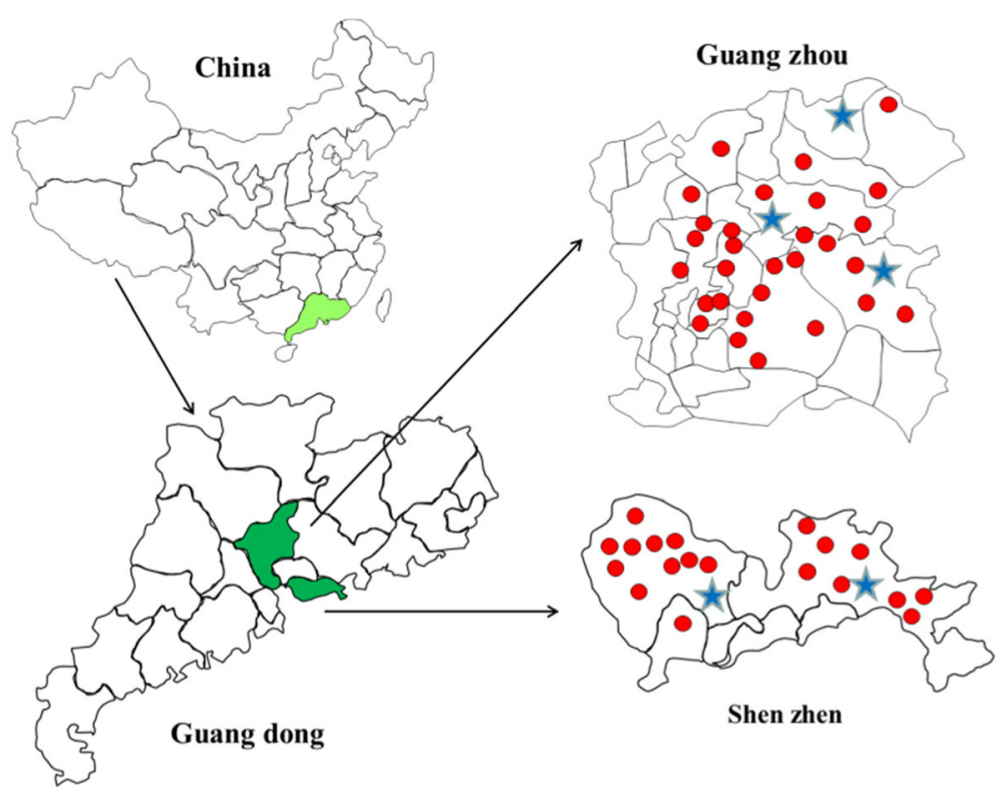

Fig. 1 Location of the five villages and 48 restaurants within Guangdong Province in southern China selected as study sites (blue star: village; red dot: restaurant)

identifications in the village; in addition, informants were presented with freshly pressed or gathered plant materials, so the species identifications could be confirmed. During all interviews, the interviewees were asked to speak freely about herb materials to allow us to acquire a list of those species used in making CSCS. In addition, when the interviewees permitted it, samples were collected with the help of local guides. Interviewees were given the option to answer the following questions about each plant species: (1) Have you ever used this plant for making CSCS or not? (2) How often do you eat it? (3) Did you sell or buy this plant? (4) Where do you gather this plant? (5) What plant part do you use of this plant? (6) What is the function of this plant in CSCS? (7) How do you prepare this plant for decoction? (8) How do you obtain plants to cure and prevent diseases in your daily life? (9) Which plants have you used during your lifetime to make CSCS, etc.? Finally, group discussions with key informants were organized separately from the 63 interviews in the five villages. Notes and photos were taken to record the relevant information provided by the informants; digital voice recorders and cameras were used to record the plants and activities of informants as they gathered plants in the field. We collected three specimens of each wild plant. Plants cultivated in home gardens were not used as voucher specimens. For those gathered from the wild and then planted in kitchen gardens, we also gathered the same species of plants from the wild. Voucher specimens of all wild plants available during field investigations were deposited in the Ethnobotany Lab of Minzu University of China. Plant identification was based on the Flora of China, and a review of specimens at PE, the herbarium of the Institute of Botany, Chinese Academy of Sciences, Beijing, China.

\section{Statistical analysis}

Mention Index (QI), frequency of use index (FUI), and Economic Index (EI) were adopted to develop and evaluate a cultural importance index for each plant species [8]. We use questions 1, 2, and 3 above to calculate the QI, FUI, and EI for each species where QI = number of mentions/ number of informants. For FUI and EI, the final value of each plant is the average of all informant responses. For the details of the calculation method see Table 1 .

Table 2 lists the ethnobotanical information for each plant, including scientific name, Chinese name, Cantonese

Table 1 Categorization of answers and values used for the cultural significance indices

\begin{tabular}{lll}
\hline Index & Answer & Value \\
\hline QI & Not mentioned & 0 \\
& Mentioned & 1 \\
& Never & 0 \\
& Less than once a month & 2.5 \\
& Once a month & 5 \\
& 2-3 times a month & 7.5 \\
& 4 or more a month & 10 \\
El & He/she does not sell or buy it & 0 \\
& He/she sells or buys it occasionally at low prices & 3.33 \\
& He/she sells or buys it regularly & 6.67 \\
& He/she sells or buys it at high prices & 10 \\
\hline
\end{tabular}




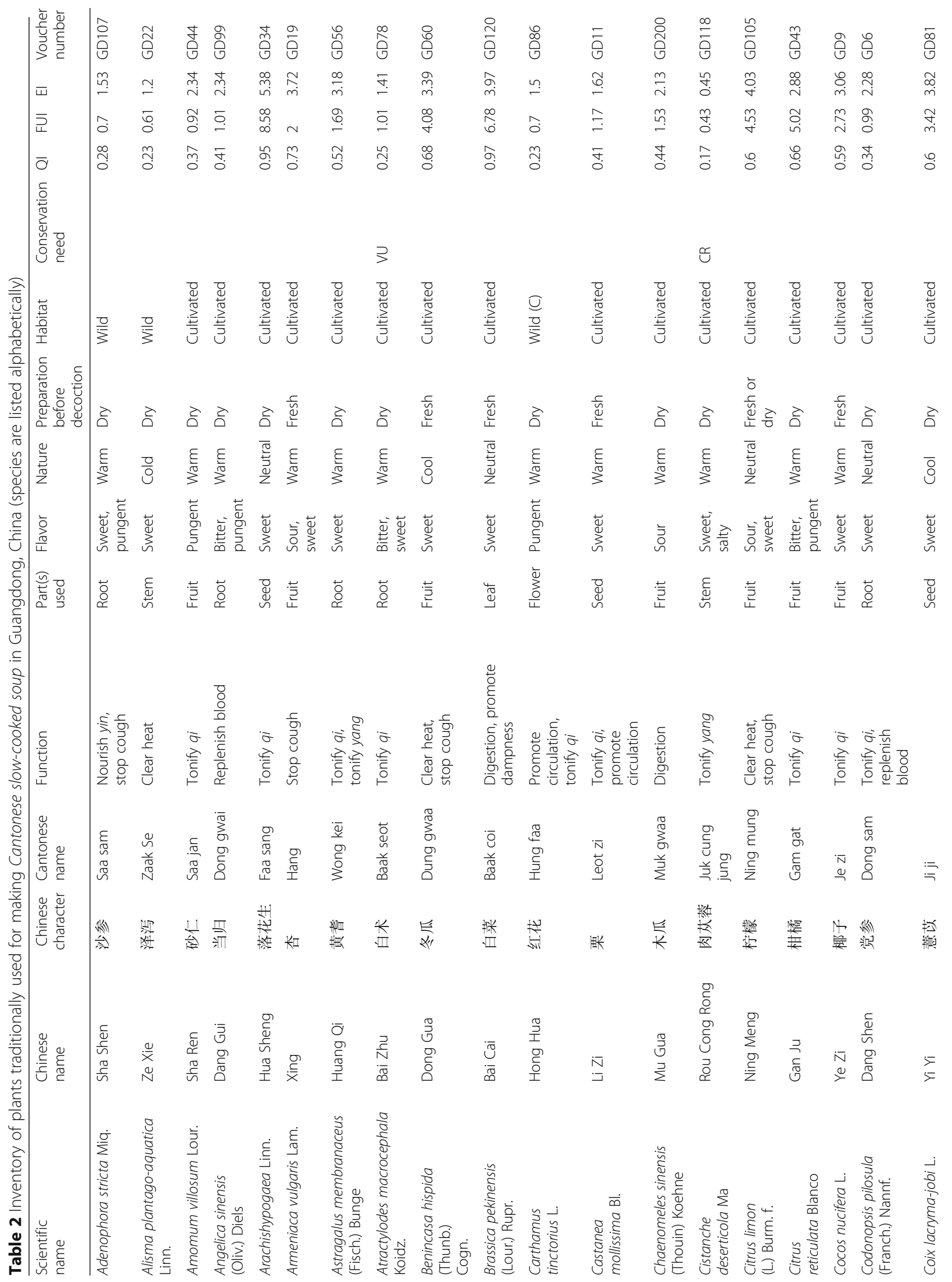




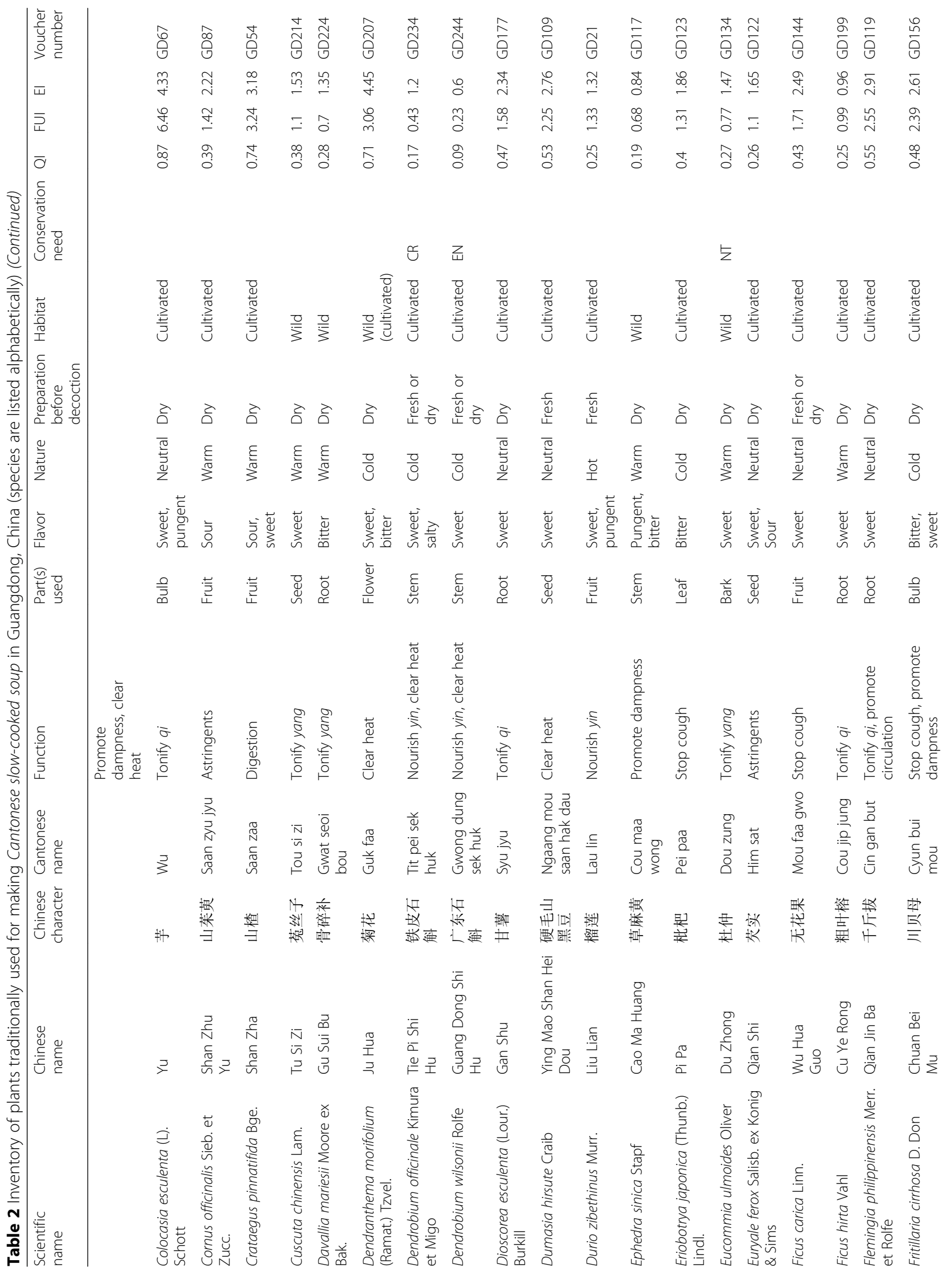




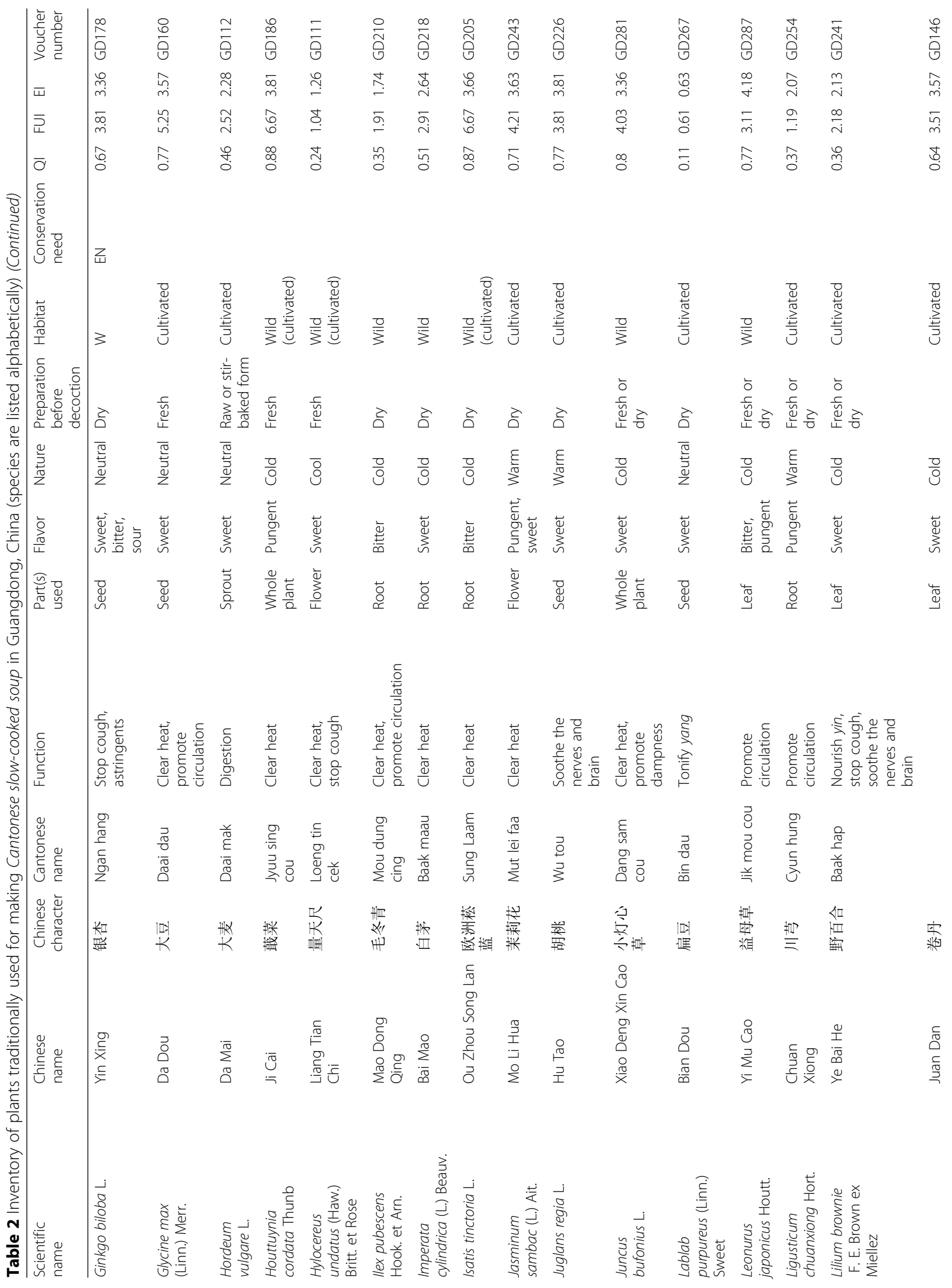




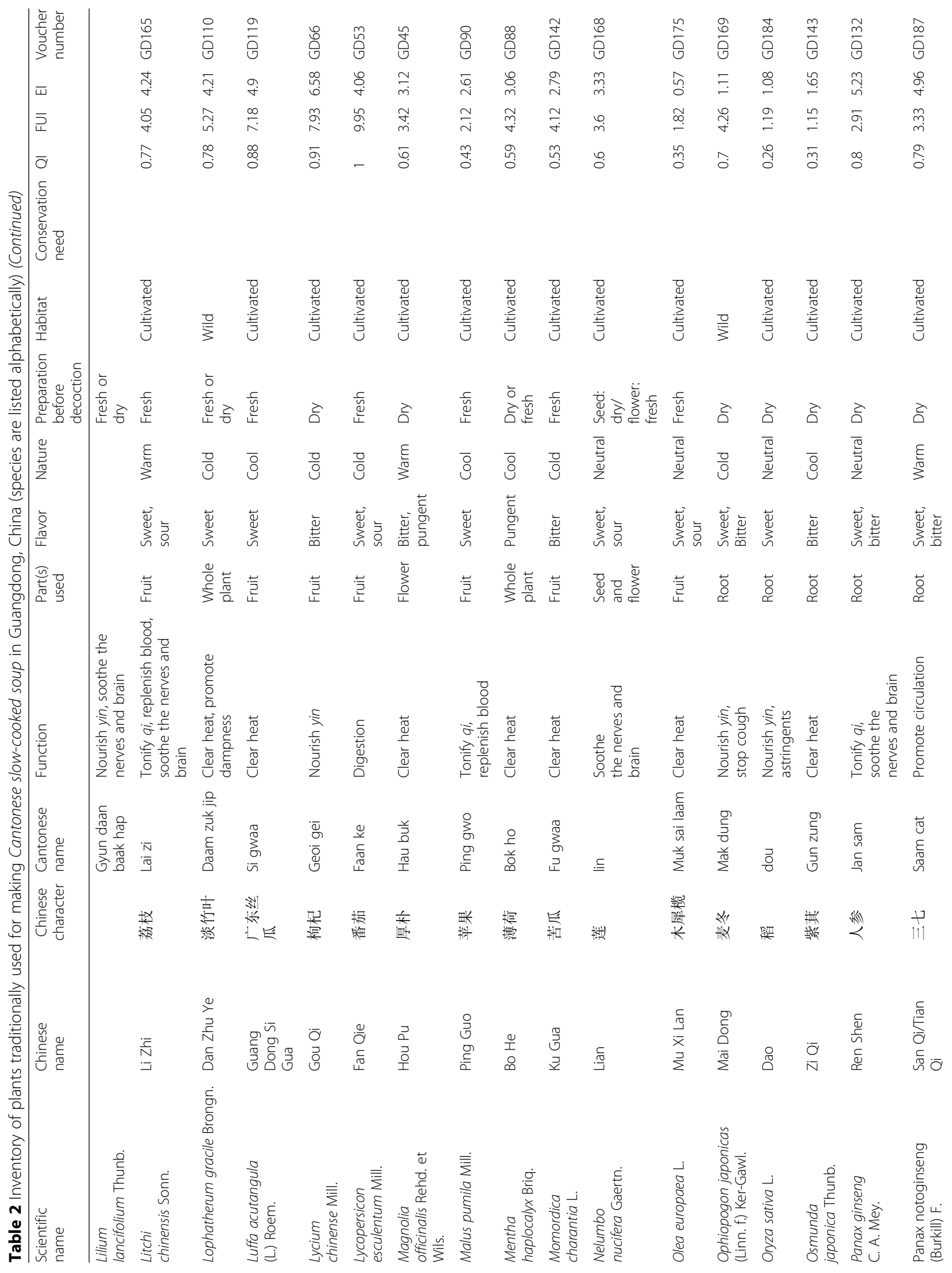




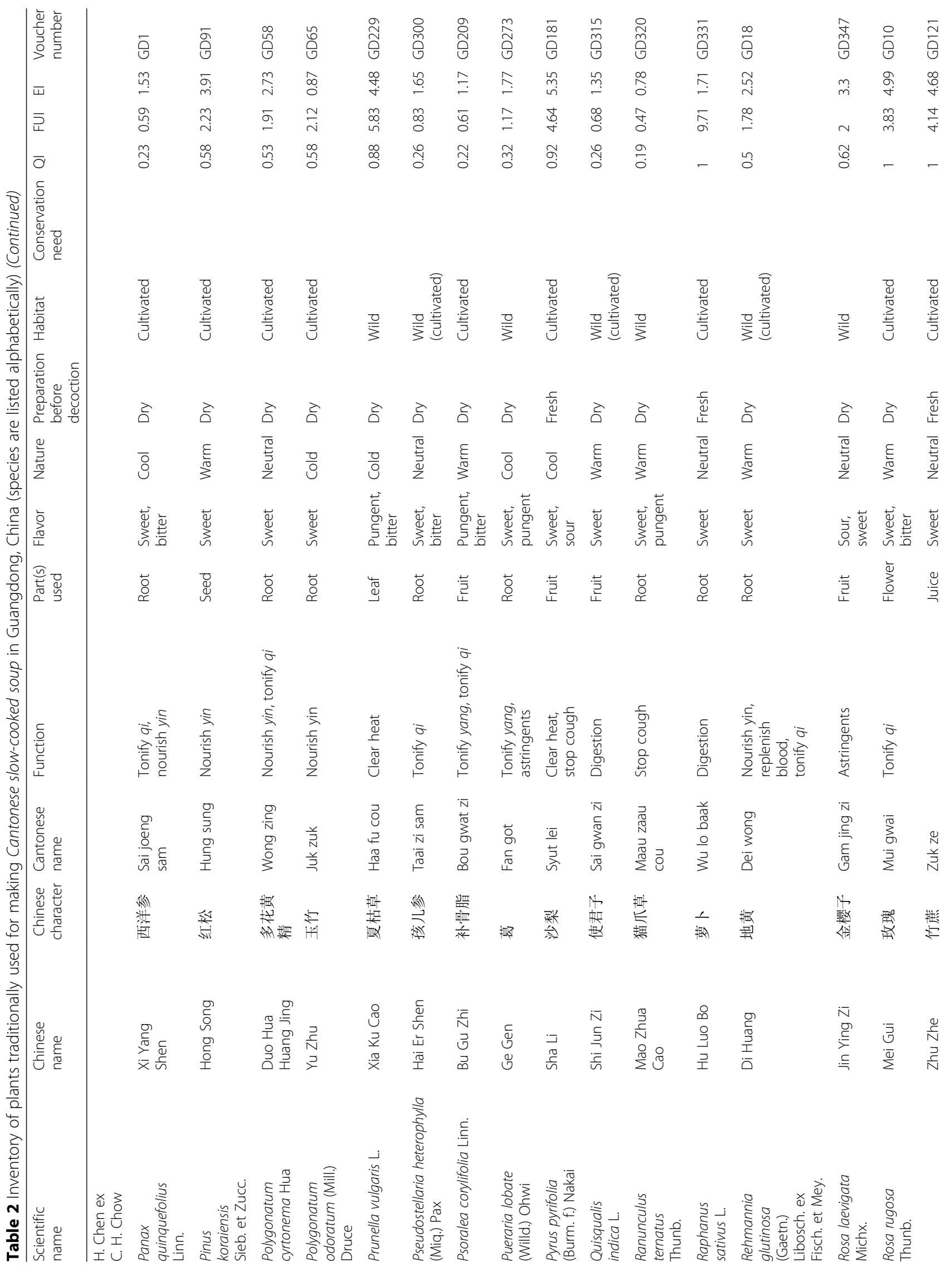




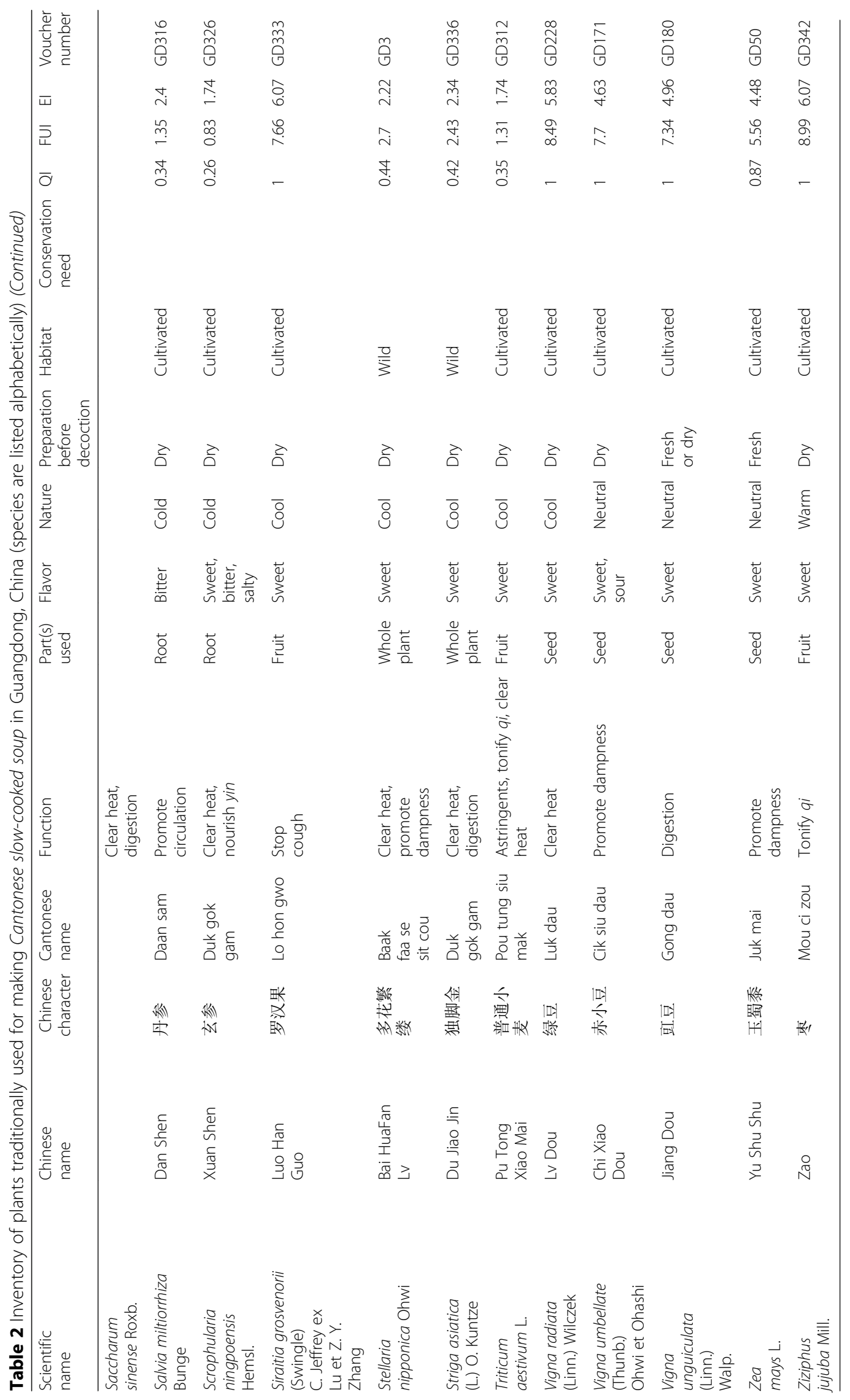


name, function, part(s) used, flavor, nature, preparation before decoction, habitat, conservation need, QI, FUI, and EI based on those defined by the Chinese Pharmacopoeia (National Pharmacopoeia Committee, 2010) and our ethnobotanical surveys. We analyzed the relationship between plant nature, flavor, and function with Apriori and Excel [9]; Apriori is a frequently used item set algorithm that is used for mining association rules. Weka 3.7 software was used to run the association rules program.

\section{Results and discussion}

\section{Diversity of plants used in CSCS}

Our ethnobotanical surveys documented 113 kinds of plants or plant parts, as defined below, used as ingredients in CSCS (Table 4), including ingredients from 97 species in 90 genera and 46 families (Table 2). In terms of the number of species, the eight species found in each caused the Gramineae and Rosaceae to rank first, followed by seven species each in the Fabaceae and Liliaceae (Fig. 2). The ingredients used in CSCS refer not only to whole herbaceous plants but also to the leaf, bark, root, seed, fruit, stem, bulb, juice, stigma, and flower. Root and fruit were used most commonly. Among these 97 species, 28 and 26 species were collected for the harvesting of roots and fruits, respectively (Fig. 3). Local people also prefer to preserve plants by drying for later use as food materials.

We checked the status of the plant species used in CSCS by following the evaluation criteria established by the International Union for Conservation of Nature (Table 2). Six species are listed on the "China red list"; Dendrobium officinale Kimura et Migo and Cistanche deserticola Ma are CR (critically endangered), Dendrobium wilsonii Rolfe is listed as EN (endangered), and

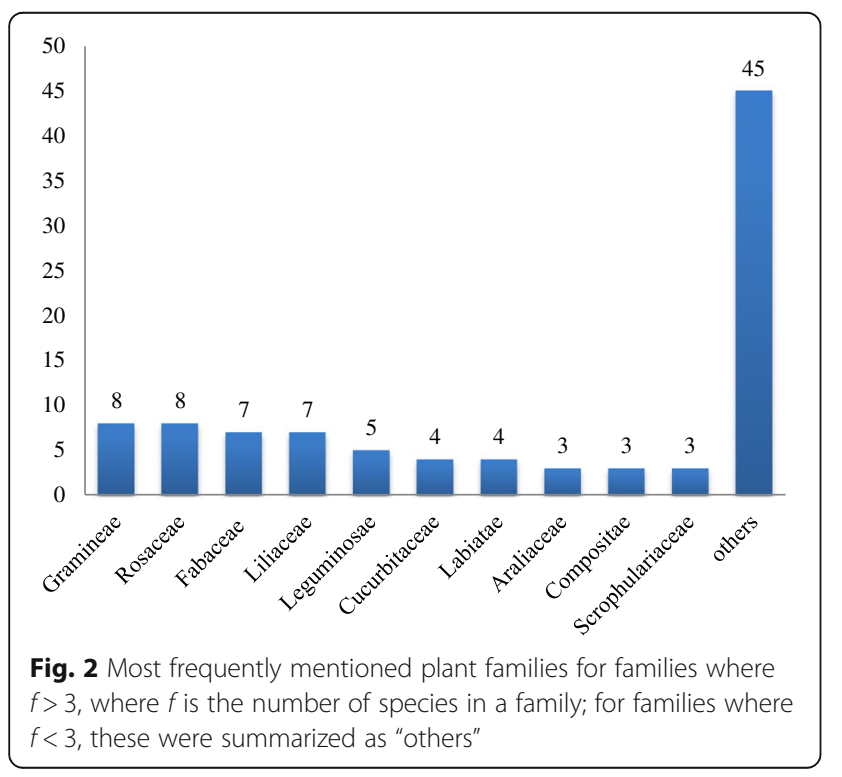

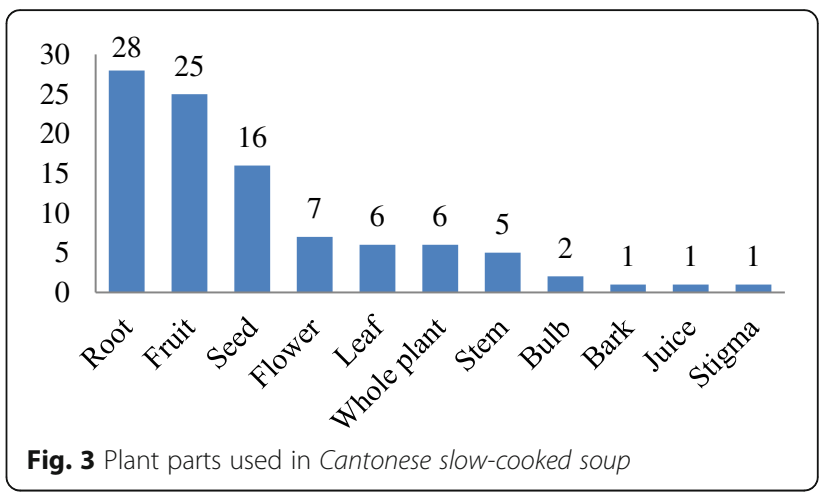

Atractylodes macrocephala Koidz. is VU (vulnerable). The remaining 91 species are in the "least concern" category. For the six endangered or vulnerable wild species, reasonable cultivation protocols and ex situ conservation methods need to be established as soon as possible.

The QI of the 97 species in the present study varied between 9 and $100 \%$. The QIs of 46 species were ranked at $0-50 \%(\sim 47.4 \%)$ and were $51-99 \%$ for 42 species $(\sim$ $43.3 \%)$; only nine species had a QI of $100 \%$ ( 9.3\%). The nine species mentioned above are familiar to almost everyone and include Lycopersicon esculentum Mill., Vigna umbellata (Thunb.) Ohwi et Ohashi, Saccharum sinense Roxb., Vigna unguiculata (Linn.) Walp., Rosa rugosa Thunb., Vigna radiata (Linn.) Wilczek, Raphanus sativus L., Siraitia grosvenorii (Swingle) C. Jeffrey ex Lu et Z. Y. Zhang, and Ziziphus jujuba Mill.

The FUI varied between 0.23 and 9.95. Nineteen species $(\sim 19.6 \%)$ were used more than once a month (FUI > $5)$. Table 2 clearly shows that the most frequently mentioned species were also the most commonly used, with the exceptions of $R$. rugosa $(\mathrm{FUI}=3.83$ ) and $S$. sinense $(\mathrm{FUI}=4.14)$. Fifty-one species were used only occasionally in some years $(\mathrm{FUI}<2.5)$; they are relatively somewhat difficult to obtain either by collection or through commerce.

The EI varied between 0.45 and 6.58. Also, 89 species had an appreciable economic importance $(E I>1)$. Lycium chinense Mill. had the highest EI value $(E I=$ 6.58); L. chinense is very significant because most people like to add it to CSCS to flavor the soup and nourish the body.

\section{Function and five elements of plants}

Chinese people attached great importance to the therapeutic role of food during the early stages of the development of Chinese medicine [10]. CSCS has the concomitant function of serving as both food and medicine based on past experience and the theory of TCM. In the present study, the medicinal functions of CSCS can be classified into 11 categories (Table 2 and Fig. 4). In TCM, " $q i$ " is considered to be a natural energy and 


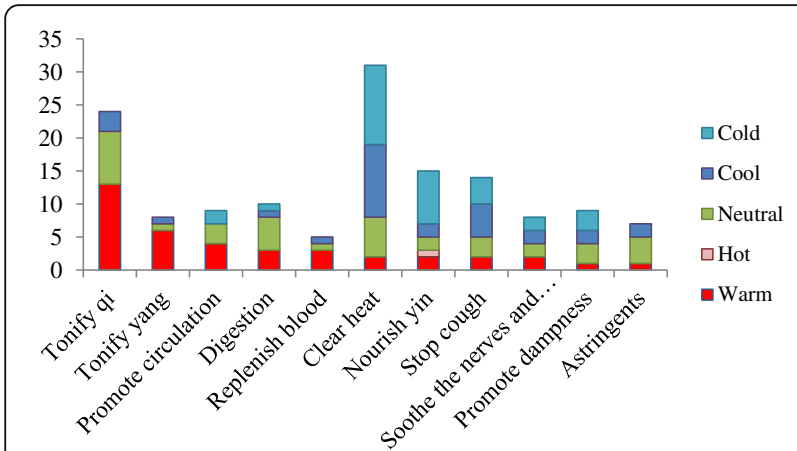

Fig. 4 The relationship between five natures (cold, cool, neutral, warm, and hot) and function of plants in CSCS

the central underlying principle of life. Symptoms of various illnesses are believed to be the product of deficiencies or imbalances in the $q i$ of the organs of the body [11]. If a qi deficiency exists in the spleen, a person will be tired and experience a loss of appetite. If a qi deficiency occurs in the lung, a person will experience shortness of breath and cough, have pale skin color, and sweat spontaneously. The Cantonese often relieve these types of imbalances by adjusting the circulation of $q i$ using food therapy. During our field surveys, we found 24 species involved in tonifying a person's qi (Fig. 4). In addition, some kinds of CSCS have significant effects in promoting digestion, dampness, and circulation as well as in tonifying a person's yang; these soups will have an astringent, soothing effect on the nerves and brain while replenishing the blood. Chinese philosophy considers yin and yang to be the two complementing principles of life; yin has the female characteristics of earth, cold, and darkness, and yang has the male characteristics of heaven, heat, and light. Any one person has both yin and yang, and these characteristics need to be balanced to maintain good health.

Although the precepts of Chinese food therapy are neither systematic nor identical in different times and places, some basic concepts have been isolated. The Chinese Pharmacopoeia (2010) classifies herbs as having five natures and five flavors based on the five elements theory, which determines their usage. The five natures (hot, warm, cool, cold, and neutral) are summarized mainly from the body's response after Chinese herbs are consumed [12]. In addition, herbs are classified into five flavors by their efficacy, using their true taste [12] including sweet, bitter, sour, pungent, and salty [13]. The five elements theory is similar with the concept of organoleptic characteristics introduced by Nina Etkin [14], how people use taste to select food or medicine; the taste of plants can define the curing properties or specific diseases of food or medicine, for example, sour tastes are useful for curing fever and nausea. In this study, each herb was linked with the theory of the five elements (Table 3). The natures of these 97 species range from cold (22 species), cool (16), neutral (27), warm (31), and hot (only Durio zibethinus Murr.). Because Guangdong is located in the East Asia monsoon region, it experiences a hot and humid climate. Practitioners of TCM hold that inner heat will accumulate in summer, and this causes many types of illness. However, many people prefer to select cool and cold herbs to clear heat from the body. In our study, the most common function of herbs related to their nature was clearing heat, with 31 plant species having this function. Also, a small amount of a hot herb was often used in CSCS, which is consistent with the ethnobotanical survey conducted here.

We analyzed the relationship between plant nature and function. Thirty-eight species having a cool or cold nature, among which 23 species are mainly used to clear heat, account for $60.5 \%$. In addition, we can see that the warm herbs are mainly used to tonify $q i$ and yang, which accounts for $61.3 \%$ of all herbs analyzed (Fig. 4). Aside from tonifying $q i$ and clearing heat, neutral herbs are mainly used to aid digestion and as astringents. However, no definite corresponding relationship was found to exist between nature and function.

In TCM, an herb with a sour taste would be assumed to be astringent; an herb with a bitter taste would be useful to eliminate dampness; pungent substances are thought to induce sweat; sweetness is supplementing, harmonizing, and moistening; and saltiness can soften hard masses [13]. In this study, 75, 26, 14, 18, and 3 species were classified as sweet, bitter, sour, pungent, and salty, respectively. We tried to find the corresponding relationship between flavor and function. Here, we indicated that sweet, bitter, and pungent herbs can be used as astringents and not just sour herbs. In addition, the main functions of sour herbs are clearing heat, stopping cough, and helping digestion. The main functions of sweet herbs are clearing heat, tonifying $q i$, nourishing yin, and stopping a cough. The main functions of bitter herbs are clearing heat, tonifying $q i$, nourishing yin, stopping a cough, and promoting circulation. The main functions of pungent herbs are clearing heat and tonifying qi (Fig. 5). Generally, clearing heat is the main

Table 3 The relationship between five plant natures and five plant flavor

\begin{tabular}{llllll}
\hline Nature & Sweet & Bitter & Sour & Salty & Pungent \\
\hline Neutral & 25 & 3 & 7 & 0 & 1 \\
Warm & 21 & 8 & 5 & 1 & 11 \\
Cold & 14 & 11 & 1 & 2 & 3 \\
Cool & 14 & 2 & 1 & 0 & 2 \\
Hot & 1 & 0 & 0 & 0 & 1 \\
\hline
\end{tabular}




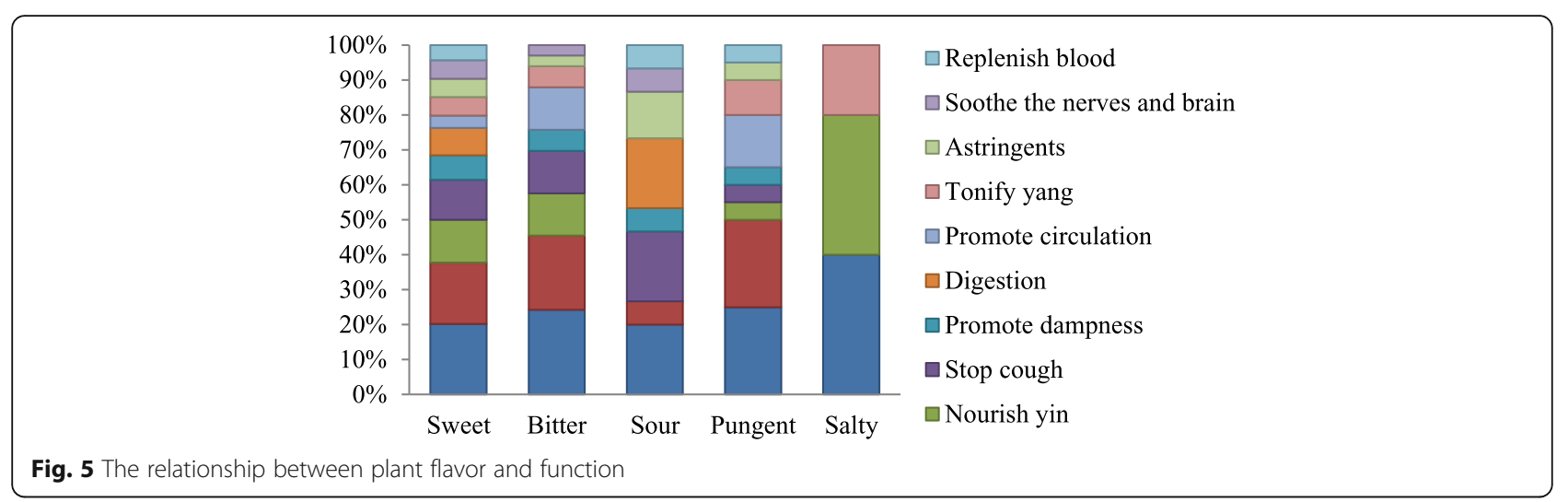

function of all herbs. It seems that there is no obvious connection between flavor and function. In fact, substances may also have more than one flavor. For example, Angelica sinensis (Oliv.) Diels is sweet and pungent, Lycopersicon esculentum Mill. is sweet and sour, and Scrophularia ningpoensis Hemsl. is sweet, bitter, and salty. In addition, each herb has its unique nature. Chinese herbal nature is an important part of TCM theory; a single characteristic (a nature, flavor, element, function, etc.) or two such characteristics cannot reveal the internal law of a particular herb systematically. Also, the 97 species discussed here cannot fully reveal the internal law; additional species will need to be analyzed. The relationship between each of the five elements of an herb and its function needs to be studied comprehensively, with the discussion not only confined to CSCS materials. In addition, we should combine the flavor and nature of an herb to explain the complicated relationship between the five elements and function and not separate flavor from nature.

Modern scientific research has been undertaken on the five natures since 1960, mainly in China and Japan, with a focus on pharmacodynamic and substantial foundational research [12]. So far, no definitive compatibility of the five elements and function has been found for Chinese medicinal herbs. The experience from ethnobotanical research related to CSCS will supply some materials for studying the relationship between the five elements and function; this will help to match ingredients with different symptoms.

\section{How to choose a type of soup?}

Cantonese people usually match ingredients based on the symptoms, medicinal effect, seasonal changes, physical quality, job, age, and gender of a patient to help people keep physically fit and to prevent and cure diseases.

(1) Soup choice depends on the symptoms: Herbs comprise most of the ingredients in CSCS. Chinese medicine emphasizes matching the remedy to the case [12], so the Cantonese will choose different soups for patients with different symptoms. For example, a mix of Ziziphus jujuba Mill. and Angelica sinensis (Oliv.) Diels or Leonurus japonicus Houtt. was used to regulate menstruation; a mix of Ligusticum chuanxiong Hort. and Dumasia hirsuta Craib was used to stop coughing and replenish qi; see Table 2 for details.

(2) Soup choice depends on the season: The Cantonese choose different soups in different seasons. In spring or summer, the Cantonese tend to choose plants to nourish the liver, such as $L$. chinense and Cuscuta chinensis Lam., or to nourish the yin, such as S. ningpoensis, D. wilsonii, and Polygonatum odoratum (Mill.) Druce. In autumn or winter, the Cantonese tend to choose plants to moisten the lungs, such as Lilium brownii F. E. Brown ex Miellez, Polygonatum cyrtonema Hua, Pinus koraiensis Sieb. et Zucc., and Panax ginseng C. A. Mey., or to tonify the kidneys, such as Rehmannia glutinosa (Gaetn.) Libosch. ex Fisch. et Mey., Davallia mariesii Moore ex Bak., and Eucommia ulmoides Oliver.

(3) Soup choice depends on physical quality: TCM contains nine kinds of physical qualities known as moderation, qi deficiency, yang deficiency, phlegm-dampness, blood stasis, qi stagnation, yin deficiency, damp-heat, and allergic qualities [15]. In our field surveys, menu nos. 77 and 100 are suitable for the qi deficiency group; menu nos. 1, 5, 75, 96, 97, and 99 are suitable for the yang deficiency group; menu nos. 2 and 101 are suitable for the phlegm-dampness group; menu nos. 15, 73, 102, and 103 are suitable for the blood stasis group; and nos. 104 and 105 are suitable for the qi stagnation group (Table 4). Epidemiological studies have shown 14$50 \%$ of people with hypertension have a $y$ in deficiency. Shen et al. indicated that Chinese food therapy can restore the constitution of the body with 
Table 4 Menus documented in this study

\begin{tabular}{|c|c|c|}
\hline Menu no. & Plant ingredients (Latin name) & Other ingredients (English name) \\
\hline 1 & $\begin{array}{l}\text { Codonopsis pilosula, Dioscorea fordii, } \\
\text { Zingiber officinalis }\end{array}$ & Quail, pork \\
\hline 2 & Ficus hirta, Flemingia philippinensis & Chicken \\
\hline 3 & Dumasia hirsuta Craib & Crucian, chicken \\
\hline 4 & Cornus officinalis, Euryale ferox & Pork \\
\hline 5 & Dioscorea fordii & Crucian, pork \\
\hline 6 & $\begin{array}{l}\text { Dioscorea fordii, Euryale ferox, Lycium chinense, } \\
\text { Adenophora stricta, Polygonatum odoratum, Ziziphus } \\
\text { jujuba, Zingiber officinalis }\end{array}$ & Squab, pork \\
\hline 7 & Striga asiatica & Pork \\
\hline 8 & Hordeum vulgare & Duck kidney \\
\hline 9 & $\begin{array}{l}\text { Pseudostellaria heterophylla, Ficus carica, } \\
\text { Ziziphus jujuba, Zingiber officinalis }\end{array}$ & Pork \\
\hline 10 & Amomum villosum & $\begin{array}{l}\text { Pork tripe, chicken, } \\
\text { Hericium erinaceus }\end{array}$ \\
\hline 11 & Amomum villosum & Crucian \\
\hline 12 & $\begin{array}{l}\text { Castanea mollissim, Dioscorea fordii, } \\
\text { Ziziphus jujuba, Zingiber officinalis }\end{array}$ & Trotters \\
\hline 13 & $\begin{array}{l}\text { Brassica pekinensis, Euryale ferox, Coix lacryma-jobi, } \\
\text { Ziziphus jujuba, Citrus reticulata, Zingiber officinalis }\end{array}$ & Duck, tofu \\
\hline 14 & Pueraria lobata & Dace \\
\hline 15 & Vigna umbellata, Stellaria nipponica & \\
\hline 16 & $\begin{array}{l}\text { Triticum aestivum, Codonopsis pilosula, Dioscorea fordii, } \\
\text { Zingiber officinalis }\end{array}$ & Pork, beef \\
\hline 17 & Artemisia scoparia & Crucian \\
\hline 18 & Rosa laevigata, Alisma plantago-aquatica & Pork \\
\hline 19 & Raphanus sativus, Zingiber officinalis & Duck \\
\hline 20 & Chaenomeles sinensis, Zingiber officinalis & Duck, pork \\
\hline 21 & $\begin{array}{l}\text { Adenophora stricta, Dioscorea fordii, } \\
\text { Polygonatum odoratum, } \\
\text { Zingiber officinalis }\end{array}$ & Goose, pork \\
\hline 22 & Dumasia hirsuta, Citrus reticulata, Zingiber officinalis & Carp, pork \\
\hline 23 & Lilium lancifolium, Citrus reticulata, Zingiber officinalis & Crucian, pork \\
\hline 24 & Armeniaca vulgaris & Crocodile \\
\hline 25 & Eriobotrya japonica (leaves) & Fish \\
\hline 26 & Chaenomeles sinensis, Zingiber officinalis & Cuttlefish, pork \\
\hline 27 & Astragalus membranaceus, Oryza sativa var. glutinosa (root) & Fish \\
\hline 28 & Vigna unguiculata, Zingiber officinalis & Fish \\
\hline 29 & Oryza sativa var. glutinosa (root), Pseudostellaria heterophylla & Loach \\
\hline 30 & Polygonatum cyrtonema, Zingiber officinalis & Oyster, chicken \\
\hline 31 & $\begin{array}{l}\text { Polygonatum odoratum, Adenophora stricta, } \\
\text { Coix lacryma-jobi, Zingiber officinalis }\end{array}$ & Pork, tendon \\
\hline 32 & $\begin{array}{l}\text { Armeniaca vulgaris, Pyrus pyrifolia, } \\
\text { Ephedra sinica, } \\
\text { Ziziphus jujuba }\end{array}$ & Pork \\
\hline 33 & Malus pumila, Ephedra sinica, Ziziphus jujuba & Pork, tremella \\
\hline 34 & Olea europaea & Conch, pork \\
\hline 35 & Glycine max, Sauropus spatulifolius (leave) & Crucian \\
\hline
\end{tabular}


Table 4 Menus documented in this study (Continued)

\begin{tabular}{|c|c|c|}
\hline Menu no. & Plant ingredients (Latin name) & Other ingredients (English name) \\
\hline 36 & Panax quinquefolius & Pork \\
\hline 37 & $\begin{array}{l}\text { Ginkgo biloba (fruit), Nelumbo nucifera, } \\
\text { Zingiber officinalis }\end{array}$ & Chicken \\
\hline 38 & Glycine max, Momordica charantia & Pork ribs \\
\hline 39 & $\begin{array}{l}\text { Raphanus sativus, Ziziphus jujuba, } \\
\text { Citrus reticulata, } \\
\text { Zingiber officinalis }\end{array}$ & Pork ribs \\
\hline 40 & $\begin{array}{l}\text { Nelumbo nucifera, Luffa acutangula, } \\
\text { Zingiber officinalis }\end{array}$ & Chicken \\
\hline 41 & $\begin{array}{l}\text { Panax quinquefolius, Dioscorea fordii, } \\
\text { Ziziphus jujuba, Zingiber officinalis }\end{array}$ & Squab \\
\hline 42 & Vigna radiata, Lilium lancifolium, Panax quinquefolius & Squab \\
\hline 43 & $\begin{array}{l}\text { Arachis hypogaea, Astragalus membranaceus, } \\
\text { Ziziphus jujuba }\end{array}$ & Beef \\
\hline 44 & $\begin{array}{l}\text { Nelumbo nucifera, Litchi chinensis, } \\
\text { Zingiber officinalis }\end{array}$ & Duck \\
\hline 45 & $\begin{array}{l}\text { Dendrobium wilsonii, Dioscorea fordii, } \\
\text { Lycium chinense, Citrusÿeticulate }\end{array}$ & Pork \\
\hline 46 & Dendrobium wilsonii, Pyrus pyrifolia & Duck \\
\hline 47 & $\begin{array}{l}\text { Dendrobium officinale, Ophiopogon japonicus, } \\
\text { Ziziphus jujuba }\end{array}$ & Pork \\
\hline 48 & Dendrobium wilsonii, Lycium chinense & Pork liver \\
\hline 49 & Angelica sinensis, Ziziphus jujuba & \\
\hline 50 & Leonurus japonicas, Ziziphus jujuba & \\
\hline 51 & Pinus koraiensis, Panax quinquefolius & Chicken or pork \\
\hline 52 & Pinus koraiensis & Pork \\
\hline 53 & Arachis hypogaea, Citrus reticulata & Pork \\
\hline 54 & Olea europaea, Castanea mollissima, Raphanus sativus & Quail, pork \\
\hline 55 & $\begin{array}{l}\text { Hylocereus undatus (flower), Imperata cylindrica, } \\
\text { Armeniaca vulgaris, Ziziphus jujuba }\end{array}$ & Pork lung \\
\hline 56 & Dioscorea fordii, Ziziphus jujube, Zingiber officinalis & Pork \\
\hline 57 & Laminaria japonica, Vigna unguiculata, Panax notoginseng & $\begin{array}{l}\text { A: scorpion, pork; } \\
\text { B: squab }\end{array}$ \\
\hline 58 & $\begin{array}{l}\text { Vigna radiata, Lilium lancifolium, Dendrobium officinale, } \\
\text { Panax quinquefolius }\end{array}$ & \\
\hline 59 & Vigna radiate, Momordica charantia & Pork \\
\hline 60 & Lycium chinense, Zingiber officinalis, Allium fistulosum & Beef \\
\hline 61 & Quisqualis indica & Pork \\
\hline 62 & Dendrobium officinale, Polygonatum odoratum, Adenophora stricta & Pork \\
\hline 63 & Glycine max, Cocos nucifera, Ficus carica, Zingiber officinalis & Chicken \\
\hline 64 & Ranunculus ternatus, Zingiber officinalis & Pork \\
\hline 65 & Eucommia ulmoides, Psoralea corylifolia, Zingiber officinalis & Pork ribs \\
\hline 66 & Dioscorea fordii, Zingiber officinalis & Fish, pork \\
\hline 67 & $\begin{array}{l}\text { Lablab purpureus, Arachis hypogaea, Zea mays, } \\
\text { Zingiber officinalis }\end{array}$ & Fish, pork \\
\hline 68 & Ficus carica, Arachis hypogaea, Zingiber officinalis & Pork, tripe \\
\hline 69 & Durio zibethinus, Zingiber officinalis & Crucian \\
\hline 70 & Dioscorea fordii, Euryale ferox, Nelumbo nucifera & Hippocampus, pork \\
\hline
\end{tabular}


Table 4 Menus documented in this study (Continued)

\begin{tabular}{|c|c|c|}
\hline Menu no. & Plant ingredients (Latin name) & Other ingredients (English name) \\
\hline 71 & $\begin{array}{l}\text { Ilex pubescens, Lycium chinense, Cuscuta chinensis, } \\
\text { Rehmannia glutinosa, Zingiber officinalis }\end{array}$ & Pork \\
\hline 72 & $\begin{array}{l}\text { Lycopersicon esculentum, Daucus carota subsp. sativus, } \\
\text { Zingiber officinalis, Allium fistulosum }\end{array}$ & Pork \\
\hline 73 & Ligusticum chuanxiong, Dumasia hirsuta & Pork \\
\hline 74 & Ranunculus ternatus, Prunella vulgaris, Glycine max & Pork \\
\hline 75 & Dendrobium officinale, Panax quinquefolius, Dioscorea fordii & Chicken or pork \\
\hline 76 & $\begin{array}{l}\text { Saccharum sinense, Raphanus sativus, Citrus reticulata, } \\
\text { Zingiber officinalis }\end{array}$ & Pork \\
\hline 77 & $\begin{array}{l}\text { Codonopsis pilosula, Lilium lancifolium, } \\
\text { Zingiber officinalis }\end{array}$ & Squab \\
\hline 78 & Euryale ferox, Zingiber officinalis & Chitterlings, scallops \\
\hline 79 & Nelumbo nucifera, Zingiber officinalis & Carp \\
\hline 80 & Fritillaria cirrhosa, Eriobotrya japonica (leaves) & Fish, pork \\
\hline 81 & Salvia miltiorrhiza & Chicken \\
\hline 82 & Nelumbo nucifera, Castanea mollissima, Zingiber officinalis & Pork kidney \\
\hline 83 & Armeniaca vulgaris, Pyrus pyrifolia, Lilium lancifolium & Goose \\
\hline 84 & $\begin{array}{l}\text { Dumasia hirsuta, Triticum aestivum, Rehmannia glutinosa, } \\
\text { Zingiber officinalis, Citrus reticulata }\end{array}$ & Oyster, pork \\
\hline 85 & $\begin{array}{l}\text { Euryale ferox, Juglans regia, Dioscorea fordii, } \\
\text { Zingiber officinalis }\end{array}$ & Pork kidney \\
\hline 86 & $\begin{array}{l}\text { Astragalus membranaceus, Ziziphus jujube, } \\
\text { Zingiber officinalis }\end{array}$ & Eel, pork kidney \\
\hline 87 & Ficus carica, Ziziphus jujube, Zingiber officinalis & Chicken \\
\hline 88 & Colocasia esculenta, Zingiber officinalis & Pork, scallops \\
\hline 89 & Allium fistulosum, Zingiber officinalis & Chicken, mushroom \\
\hline 90 & Eucommia ulmoides, Cistanche deserticola & Pork \\
\hline 91 & $\begin{array}{l}\text { Nelumbo nucifera, Vigna umbellata, } \\
\text { Zingiber officinalis, Ziziphus jujuba }\end{array}$ & Squid, pigeon \\
\hline 92 & Mentha haplocalyx, Magnolia officinalis & Pork \\
\hline 93 & Atractylodes macrocephala & Crucian \\
\hline 94 & Houttuynia cordata, Siraitia grosvenorii & Pork lung \\
\hline 95 & Pyrus pyrifolia, Armeniaca vulgaris & Jellyfish \\
\hline 96 & Lycium chinense, Ziziphus jujube & Chicken \\
\hline 97 & Angelica sinensis, Zingiber officinale & Mutton \\
\hline 98 & Angelica sinensis, Rehmannia glutinosa & Squab \\
\hline 99 & $\begin{array}{l}\text { Dioscorea fordii, Raphanus sativus, Ziziphus jujube, } \\
\text { Lycium chinense }\end{array}$ & Chicken \\
\hline 100 & Panax ginseng, Ziziphus jujube, Lycium chinense & Silkie \\
\hline 101 & $\begin{array}{l}\text { Coix lacryma-jobi, Lablab purpureus, Citrus reticulate, } \\
\text { Ziziphus jujube }\end{array}$ & Squab \\
\hline 102 & Crataegus pinnatifida, Raphanus sativus & Pork feet \\
\hline 103 & Rosa rugosa, Carthamus tinctorius, Angelica sinensis & Pork \\
\hline 104 & Dendranthema morifolium, Jasminum sambac & Chicken liver, tremella \\
\hline 105 & Citrus limon, Ziziphus jujube, Lycium chinense & Chicken \\
\hline 106 & Lophatherum gracile, Juncus bufonius, Ophiopogon japonicus & \\
\hline 107 & Rehmannia glutinosa, Scrophularia ningpoensis & Pork \\
\hline
\end{tabular}


Table 4 Menus documented in this study (Continued)

\begin{tabular}{lll}
\hline Menu no. & Plant ingredients (Latin name) & Other ingredients (English name) \\
\hline 108 & Panax notoginseng, Ziziphus jujube & Frog \\
109 & Rehmannia glutinosa, Carthamus tinctorius, Angelica sinensis & Silkie \\
110 & Davallia mariesii & Pork \\
111 & Isatis tinctoria, Osmunda japonica & Pork \\
112 & Benincasa hispida & Crucian \\
113 & Dioscorea fordii, Zea mays & \\
\hline
\end{tabular}

a yin-yang imbalance and may be beneficial in controlling blood pressure in hypertensive patients [16]. Benincasa hispida (Thunb.) Cogn., V. radiata, and Glycine $\max$ (Linn.) Merr. are good for nourishing the yin.

(4) Soup choice depends on job category: Night workers, such as taxi drivers, easily suffer from fatigue and anorexia; therefore, they should choose Crataegus pinnatifida Bge. and Citrus reticulata Blanco to increase their appetites. Workers who use computers should choose $R$. sativus, Dendranthema morifolium (Ramat.) Tzvel., and L. chinense to improve vision.

(5) Soup choice depends on age and gender: Middleaged women may have symptoms of endocrine dyscrasia, metabolic disorders, anemia, and osteoporosis caused by hormone problems; for them, the Cantonese would boil A. sinensis, R. glutinosa, $Z$. jujuba, and R. sativus to nourish the yin and tonify the blood. Middle-aged men may be given Psoralea corylifolia Linn. and E. ulmoides to tonify the yang. The metabolism of an elderly person may gradually weaken; thus, elderly people should use $Z$. jujuba and Dioscorea fordii Prain et Burkill to invigorate the spleen and stomach as well as to tonify the $q i$ and the blood.

CSCS can help to keep a person in good health; however, not everyone will want to eat it because of some taboos related to their diets. Herbs not only have nutrients but also numerous chemical components, some of which are known to have biological actions; however, others may have a potential to influence human physiology and pathophysiology, but this area of research remains unexplored [10]. Codonopsis pilosula (Franch.) Nannf. can tonify the qi, replenish the blood [17], and has antitumor activity [18, 19]. Astragalus membranaceus (Fisch.) Bunge can tonify the qi and the yang [20, 21]. Panax quinquefolius Linn. possesses certain effects on tonifying the qi and nourishing the yin [22] and is active against human breast cancer [23]. Polygonatum cyrtonema Hua can tonify the qi, nourish the yin [24], and has anti-HIV properties [25]. Eucommia ulmoides Oliver can tonify the yang $[26,27]$ and improve the human immune system [28]. In this survey, the Cantonese told us that pregnant women should not eat much Armeniaca vulgaris Lam., Coix lacryma-jobi L., and Hordeum vulgare L. They told us that people who are deficient in cold of the spleen and stomach should not eat much $V$. radiata. Panax ginseng C. A. Mey. and Panax quinquefolius Linn. cannot be eaten with $R$. sativus and $C$. pinnatifida. People who suffer from superfluity syndrome or warm syndrome cannot have $C$. pilosula. Patients with acute illnesses cannot have $A$. membranaceus. The Cantonese also told us that people with frequent diarrhea should not eat P. cyrtonema, and those with kidney ailments should not eat E. ulmoides.

\section{Conclusions}

The number of groups of people with less than robust health continues to increase. In the long course of development of CSCSs, the quintessence of TCM has been adopted. Different soups have different functions. CSCS has four dimensions: social, functional, cultural, and economic. As soup materials, traditional knowledge of various plants used in CSCS was documented, including local plant name, function, part(s) used, flavor, nature, preparation before decoction, habitat, and cultural significance indices. Knowledge of these herbs used in food therapy will provide a broad socio-anthropological context related to eating. The relationships among the nature, flavor, and function of herbs seem to be related to each other but are not absolute, which will be a key point of consideration in TCM. In addition, these theories of CSCS will provide the essential basis for the analyses and clinical usage of Chinese herbs.

\section{Abbreviations}

CR: Critically endangered; CSCS: Cantonese slow-cooked soup; El: Economic Index; EN: Endangered; FUl: Frequency of use index; QI: Mention Index;

TCM: Traditional Chinese medicine; VU: Vulnerable

\section{Acknowledgments}

We are very grateful to the local people in Guangdong Province who provided invaluable information. We appreciate the funding received from the National Natural Science Foundation of China (Grant No. 31600254), the Natural Science Foundation of Jiangsu Province of China (Grant No. BK20150491), the Start-Up Fund for Advanced Talents of Jiangsu University (Grant No. 14JDG150), the School of Agricultural Equipment Engineering at 
Jiangsu University, and the Priority Academic Program Development of Jiangsu Higher Education Institutions (PAPD, [2014]37), "Youth backbone teacher training project" for young academic leaders cultivation candidates of Jiangsu University.

\section{Funding}

National Natural Science Foundation of China (Grant No. 31600254), the Natural Science Foundation of Jiangsu Province of China (Grant No. BK20150491), the National Science Foundation for Post-doctoral Scientists of China (Grant No.2017M621651), the Jiangsu Postdoctoral Sustentation Fund (Grant No. 1701070B), the Start-Up Fund for Advanced Talents of Jiangsu University (Grant No. 14JDG150), "Youth backbone teacher training project" for young academic leaders cultivation candidates of Jiangsu University, the School of Agricultural Equipment Engineering at Jiangsu University, and the Priority Academic Program Development of Jiangsu Higher Education Institutions (PAPD, [2014]37).

\section{Availability of data and materials}

We are willing to share the data generated or analyzed during the current study.

\section{Authors' contributions}

LYJ and LCL conceived of and designed the study, conducted the data collection, and interpreted the data. Literature retrieval was done by LYJ, LQ, and XDK. Field surveys were conducted by LYJ, LP, and LCL. LL and HHG analyzed the data. LYJ drafted the manuscript. All authors read and approved the final manuscript.

\section{Ethics approval and consent to participate}

We followed ethical guidelines adopted by the International Society of Ethnobiology (2008). Permissions were verbally informed by all participants in this study, including the owner of soup material store shown in the cover photo. She has declared that she has no objection to the publication of her pictures in the journal. The Human subject approval was obtained from the Institute of Ethnology and Anthropology, Minzu University of China, prior to beginning work

\section{Consent for publication}

Not applicable

\section{Competing interests}

The authors declare that they have no competing interests.

\section{Publisher's Note}

Springer Nature remains neutral with regard to jurisdictional claims in published maps and institutional affiliations.

\section{Author details}

${ }^{1}$ School of Agricultural Equipment and Engineering, Jiangsu University, Zhenjiang, Jiangsu 212013, China. ${ }^{2}$ College of Natural Resources and Environment, South China Agricultural University, Guangzhou, Guangdong 510642, China. ${ }^{3}$ Institute of Basic Theory, China Academy of Traditional Chinese Medicine, Beijing 100700, China. ${ }^{4}$ Kunming Institute of Botany, Chinese Academy of Sciences, Kunming, Yunnan 650201, China. ${ }^{5}$ College of Life and Environmental Sciences, Minzu University of China, Beijing 100081, China.

Received: 10 November 2017 Accepted: 28 December 2017

Published online: 15 January 2018

\section{References}

1. Liu YJ, Ahmed S, Long CL. Ethnobotanical survey of cooling herbal drinks from southern China. J Ethnobiol Ethnomed. 2013;9:82.

2. Cai SF. The development and research on nutritional therapy soup and diet of Hong Kong: Guangzhou University of Chinese Medicine; 2009.

3. Fulder $\mathrm{S}$, Tenne M. Ginger as an anti-nausea remedy in pregnancy the issue of safety. HerbalGram (USA). 1996;1(12):2521-31.

4. Shao Y, Wu Q, Wen H, Chai C, Shan C, Yue W, Yan S, Xu H. Determination of flavones in lophatherum gracile by liquid chromatography tandem mass spectrometry. Instrum Sci Technol. 2014;42:173-83.
5. Doan DD, Nguyen N, Doan H, Nguyen T, Phan T, Van Dau N, Grabe M, Johansson R, Lindgren G, Stjernström N. Studies on the individual and combined diuretic effects of four Vietnamese traditional herbal remedies (Zea mays, Imperata cylindrica, Plantago major and Orthosiphon stamineus). J Ethnopharmacol. 1992;36:225-31.

6. Zhang S, Cheng H, Dong J. Amino-acid and mineral composition of the seeds of Euryale ferox. Chem Nat Compd. 2011;47:490-1.

7. Maria S, Maddalena P, Piero B. Plants and traditional knowledge: an ethnobotanical investigation on Monte Ortobene (Nuoro, Sardinia). J Ethnobiol Ethnomed. 2009;5:1-14

8. Garibayorijel R, Caballero J, Estradatorres A, Cifuentes J. Understanding cultural significance, the edible mushrooms case. J Ethnobiol Ethnomed. 2007:3:1-18.

9. Yu HY, Xu CG. Relationship between nature and other properties of traditional Chinese medicine based on association rule. Chin J Exp Tradit Med Formulae. 2013;19:343-6.

10. Mclean AJ, Wahlqvist ML. Current problems in nutrition pharmacology and toxicology. Herts: John Libbey; 1988.

11. Ni M. The Yellow Emperor's classic of medicine. Boulder: Shambhala Publications; 1995.

12. Liao H, Banbury LK, Leach DN. Antioxidant activity of 45 Chinese herbs and the relationship with their TCM characteristics. Evid Based Complement Alternat Med. 2008:5:429-34

13. Ung CY, Li H, Cao ZW, Li YX, Chen YZ. Are herb-pairs of traditional Chinese medicine distinguishable from others? Pattern analysis and artificial intelligence classification study of traditionally defined herbal properties. J Ethnopharmacol. 2007;111:371-7.

14. Thornburg GK. Nina L. Etkin: edible medicines: an ethnopharmacology of food. J Agric Environ Ethics. 2011;24:92

15. Wang Q. Classification and diagnosis basis of nine basic constitutions in Chinese medicine. J Beijing Univ Tradit Chin Med. 2005;28:1-8.

16. Shen C, Pang SMC, Kwong EWY, Cheng Z. The effect of Chinese food therapy on community dwelling Chinese hypertensive patients with yindeficiency. J Clin Nurs. 2010;19:1008-20.

17. Xue-mei M. Advances in studies on Codonopsis pilosula. J Anhui Agric Sci. 2009;15:071

18. Xin T, Zhang F, Jiang Q, Chen C, Huang D, Li Y, Shen W, Jin Y, Sui G. The inhibitory effect of a polysaccharide from Codonopsis pilosula on tumor growth and metastasis in vitro. Int J Biol Macromol. 2012;51:788-93.

19. Yang C, Gou Y, Chen J, An J, Chen W, Hu F. Structural characterization and antitumor activity of a pectic polysaccharide from Codonopsis pilosula. Carbohydr Polym. 2013:98:886-95.

20. Zhang Q, Gao WY, Man SL. Chemical composition and pharmacological activities of Astragali radix. China J Chin Mater Med. 2012:37:3203.

21. Dong TT, Ma XQ, Clarke C, Song ZH, Ji ZN, Lo CK, Tsim KW. Phylogeny of Astragalus in China: molecular evidence from the DNA sequences of $5 \mathrm{~S}$ rRNA spacer, ITS, and 18S rRNA. J Agric Food Chem. 2003;51:6709-14.

22. Guo YQ, Wei GL, Zhong OM, Wang DS. Clinical application of Panax quinquefolius. Chin J Mod Drug Appl. 2011;5:128-9.

23. Wang $C$, Aung H, Zhang B, Sun S, Li X, He H, Xie J, He T, Du W, Yuan C. Chemopreventive effects of heat-processed Panax quinquefolius root on human breast cancer cells. Anticancer Res. 2008;28:2545.

24. Chen Y, Sun XS. Pharmacological research grogress in Polygonatum cyrtonema. Tradis Chin Drug Res Clin Pharmacol. 2010;21:328-30.

25. Ding JJ, Bao JK, Zhu DY, Zhang Y, Wang DC. Crystal structures of a novel anti-HIV mannose-binding lectin from Polygonatum cyrtonema Hua with unique ligand-binding property and super-structure. J Struct Biol. 2010;171:309

26. Xiao L, Zhou RG. The research progresses of Eucommia ulmoides' antihypertensive effect. Chin Med Guide. 2013;11:501-2.

27. Liu N, Shu KX, Liu CS. The domestic and abroad research progresses of Eucommia ulmoides. Med J Natl Def Forces Southwest China. 2002;12:449.

28. Feng H, Fan J, Song Z, Du X, Chen Y, Wang J, Song G. Characterization and immunoenhancement activities of Eucommia ulmoides polysaccharides. Carbohydr Polym. 2016;136:803. 